\title{
EVASÃO FISCAL E EFETIVIDADE DOS DIREITOS FUNDAMENTAIS
}

\author{
JOACIR SEVEGNANI ${ }^{1}$ \\ MARCOS LEITE GARCIA ${ }^{2}$
}

\begin{abstract}
RESUMO: O presente artigo tem por objetivo demonstrar a interferência da evasão fiscal na efetiva concretização dos direitos fundamentais. Parte-se do pressuposto de que os tributos são a base de sustentação financeira do Estado, quem tem a função de atender as demandas sociais, com ênfase àquelas alçadas constitucionalmente ao nível de direitos fundamentais. Se por um lado, a evasão fiscal se caracteriza como espécie de corrupção que visa impedir o pagamento de tributos, por outro, a efetivação dos direitos fundamentais depende, em grande medida, de recursos públicos. Embora a evasão fiscal não deva ser justificativa para a não efetivação de direitos fundamentais, sob a alegação de escassez de recursos, é inegável que a falta de investimentos interfere, ainda que indiretamente, no bem estar da sociedade. Diante disso, os direitos fundamentais precisam destacar-se como demandas inafastáveis e insuscetíveis de postergação.

PALAVRAS-CHAVE: Tributo; Estado; Evasão Fiscal; Efetividade; Direitos Fundamentais.
\end{abstract}

ABSTRACT: This article aims to demonstrate the interference of tax evasion in the effective implementation of fundamental rights. The departing point was the assumption that taxes are the base of financial support of the state, which has the function to meet social demands, with emphasis on those considered fundamental rights on a constitutional level. If on one side, tax evasion is manifested as a kind of corruption that aims to impede the payment of taxes, on the other, the enforcement of fundamental rights depends largely on public resources. Although tax evasion should not be a justification for the non-enforcement of fundamental rights under the pretext of resource scarcity,

Artigo recebido em 04.07.2011. Pareceres emitidos em 25.07.2011, 22.09.2011 e 19.10.2011. Artigo aceito para publicação em 17.06.2012.

${ }^{1}$ Doutorando em Ciência Jurídica pela Universidade do Vale do Itajaí - UNIVALI. Auditor Fiscal da Receita Estadual do Estado de Santa Catarina. Professor de Direito Tributário do Centro Universitário para o Desenvolvimento do Alto Vale do Itajaí - UNIDAVI, Rio do Sul - SC. jsevegnani@sef.sc.gov.br

Doutor em Direito. Curso realizado no Instituto de Direitos Humanos da Universidade Complutense de Madrid (Espanha) no qual foi aluno, entre outros, de Gregorio Peces-Barba, Antonio Pérez-Luño, Eusébio Fernández, Nicolás López Calera, Antonio Truyol y Serra, Joaquín Ruiz-Jiménez (Título revalidado nacionalmente). Mestre (máster-especialista) em Direitos Humanos pelo mesmo Instituto espanhol. Atualmente é professor permanente do Curso de Pós-Graduação Stricto Sensu em Ciência Jurídica e do Curso de Graduação em Direito da Universidade do Vale do Itajaí (UNIVALI), Itajaí - SC, Brasil. mleitegarcia@terra.com.br 
it is undeniable that the lack of investments interferes, even indirectly, on society's welfare. In view of this, the fundamental rights must be stated as unavoidable demands, which are insusceptible to postponement.

KEYWORDS: Taxes; State; Tax Evasion; Effectiveness; Fundamental Rights.

SUMÁRIO: Introdução; 1 Os Fundamentos da Tributação; 2 A Evasão Fiscal como Prática de Corrupção; 3 A Contribuição dos Tributos para a Efetividade dos Direitos Fundamentais; Considerações Finais; Referências.

SUMMARY: Foreword; 1 The Basis of Taxation; 2 The Practice of Tax Evasion as Corruption; 3 The Contribution of Taxes for the Effectiveness of Fundamental Rights; Concluding Remarks; References.

\section{INTRODUÇÃO}

O Estado ${ }^{3}$, como ente criado desde o início para atender às necessidades da sociedade, agindo como coordenador e organizador das ações de interesse público, foi dotado de um poder que lhe permite ser o instrumento efetivo para a consecução destes fins. Essa noção de poder acha-se intrinsecamente ligada à finalidade para o qual foi criado: a realização do bem comum.

A esse poder dá-se o nome de soberania, que se caracteriza como um elemento essencial, até mesmo imprescindível, para a existência e legitimação do Estado. É uma delegação da sociedade, para que aja de acordo com os interesses dos cidadãos. Deste modo, ao traçar normas para regular as relações dos indivíduos, o faz sustentado nessa autoridade, sem que nenhuma outra força interfira ou se oponha, devendo as pessoas que vivem dentro do seu território, obedecer às suas ordens, subordinando-se às mesmas.

O poder de instituir e exigir tributos encontra a sua legitimação na soberania que o Estado é detentor, permitindo-Ihe apropriar-se de parte do patrimônio dos cidadãos. Contudo, o Estado não pode estar desconectado dos interesses sociais, mas vinculado às funções que exerce como a manutenção da ordem, da liberdade, da justiça, da garantia da propriedade, do fortalecimento da democracia, da oferta de sistemas de previdência e assistência, enfim, voltado à implementação de políticas direcionadas ao atendimento das necessidades públicas, para que os cidadãos possam ter uma existência digna. Por outro lado, o Estado deve ser justo na instituição e exigência dos tributos, para que cada um contribua de acordo com a sua capacidade contributiva.

Deste modo, se o Estado exige tributos com o propósito de garantir a fruição de direitos aos cidadãos, significa que há uma relação entre o quantum arrecada e a sua possibilidade financeira de efetivamente materializá-los.

${ }^{3}$ Adota-se o conceito de Estado proposta por Dallari, como sendo uma "ordem jurídica soberana, que tem por fim o bem comum de um povo situado em determinado território". (DALLARI, 2001, p. 49)

DiREITOS FUNDAMENTAIS E JUSTIÇA - ANO 6, N' 19, P. 124-144, ABR./JUN. 2012 
Assim, o dever fundamental de pagar tributos representa um dos sustentáculos para a concretização dos direitos fundamentais. Ao contrário, a sonegação figura como uma chaga que deturpa a vivência em sociedade, reduzindo o sentimento de solidariedade que perpassa pelos fundamentos da tributação.

Portanto, a temática que se traz a análise visa debater a relação indissociável entre os tributos e os direitos fundamentais e, em consequência, as distorções financeiras e morais produzidas pelas práticas de evasão fiscal $^{4}$ perpetradas pelos contribuintes.

\section{OS FUNDAMENTOS DA TRIBUTAÇÃO}

Os tributos caracterizam-se como uma manifestação do poder de império do Estado, impondo obrigações pecuniárias à sociedade, retirando-lhes parte da riqueza produzida, com o propósito de realizar a atividade financeira. Esta é desempenhada pela obtenção de receitas, pela administração do produto arrecadado e, ainda, pela realização de dispêndios ou despesas. É no orçamento público que as receitas e despesas são confrontadas, objetivando uma gestão equilibrada das contas públicas.

Do ponto de vista jurídico, para Coêlho (1999, p. 381), "tributo é toda prestação pecuniária em favor do Estado ou de pessoa por ele indicada, tendo por causa um fato lícito, previsto em lei, instituidor de relação jurídica". Segundo a concepção de Torres (2000, p. 320-321), diante da ampliação dos poderes estatais que a Constituição de $1988^{5}$ concebeu para o Brasil, o conceito de tributo também deve ser alargado. Assim, o autor conceitua tributo como o:

[...] dever fundamental, consistente em prestação pecuniária, que, limitado pelas liberdades fundamentais, sob a diretiva dos princípios constitucionais da capacidade contributiva, do custo/benefício ou da solidariedade do grupo e com a finalidade principal ou acessória de obtenção de receita para as necessidades públicas ou para atividades protegidas pelo Estado, é exigido de quem tenha realizado o fato descrito em lei elaborada de acordo com a competência específica outorgada pela Constituição.

Se a tributação tem por escopo retirar uma porção da riqueza de cada cidadão para o financiamento do Estado, essa atividade deve observar determinados critérios e bases imponíveis, de forma a torná-la justa e o mais eficiente possível.

De acordo com Adam Smith, considerado um dos precursores dos fundamentos modernos da tributação, em sua obra A Riqueza das Nações,

\footnotetext{
${ }^{4}$ Para os fins deste artigo, considera-se evasão fiscal a prática de atos ilícitos, visando suprimir ou reduzir o valor do tributo devido, por meio de fraude, sob as mais diversas formas, ou mediante a omissão de informações à Administração Tributária. Será utilizada por vezes a expressão "sonegação fiscal" com o mesmo sentido de evasão fiscal.

${ }^{5}$ A expressão "Constituição de 1988" será utilizada neste texto como referência à "Constituição da República Federativa do Brasil de 1988".
} 
a exigência dos impostos dos contribuintes deve ser conformada, de forma a atender quatro máximas ou princípios fundamentais: a equidade, a certeza, a conveniência do pagamento e a economia do recolhimento.

A equidade diz respeito à necessidade do Estado exigir que cada um contribua na proporção dos rendimentos que desfruta sob a proteção do poder público. Por esta ótica, as despesas do governo são comparáveis às dos rendeiros de uma grande fazenda, onde cada um cada um contribui em proporção aos respectivos interesses e benefícios que têm na propriedade. Conclui o autor ser essa a razão para que os ricos paguem mais, pois necessitam de uma maior segurança para proteger os seus bens. A observância ou não cumprimento deste princípio resulta na igualdade ou desigualdade da tributação.

Pelo critério da certeza, as normas que fixam tributos, devem estabelecer claramente as regras que os contribuintes devem conhecer para o cumprimento das obrigações tributárias como, o quantum a que ficarão sujeitos a pagar, a data e a forma de pagamento. $\mathrm{Na}$ atualidade, é a lei que proporciona certeza e segurança ao contribuinte, de somente ser onerado nos termos que ela estabelece.

A conveniência do pagamento procura adequar o cumprimento da obrigação de recolher o tributo, ao melhor momento para o contribuinte. Desta forma, se impostos sobre aluguéis deveriam ser exigidos por ocasião do seu recebimento, pois seria o momento com maior probabilidade de pagamento, impostos sobre o consumo, que em última análise são arcados, geralmente, pelo consumidor, podem ser cobrados do vendedor após as vendas.

Por fim, a economia no recolhimento, tem por finalidade retirar das pessoas o mínimo possível de recursos, suficientes para a manutenção do Estado. Os sistemas tributários não atingem esse fim quando: a) o recolhimento dos tributos é feito a um custo tão elevado que consome a maior parte do montante arrecadado; b) a exigência de um tributo dificulta ou desestimula a iniciativa das pessoas de investir em certos setores de negócios que poderiam dar sustento e emprego a grandes multidões; c) são instituídos tributos pouco criteriosos e injustos e, penalidades elevadas para coibir o seu descumprimento de forma que o estimulo à sonegação advém, em parte, da perversidade do próprio sistema, ou seja, onde a lei primeiro cria a tentação e depois pune aqueles que a ela sucumbem e; d) os tributos são exigidos por meio de visitas frequentes dos coletores, o que pode causar vexações, opressões fiscais e incômodos desnecessários aos contribuintes.

Das proposições de Smith (1996, p. 282-284) defluiram os modernos princípios que fundamentam atualmente a tributação, destacando-se a capacidade contributiva, a igualdade, a legalidade e a não-surpresa.

A concepção de equidade foi precursora do princípio da capacidade contributiva, com a mesma configuração daquela, ou seja, uma tributação em que cada um deve contribuir na proporção de suas rendas e haveres. 
Isto significa que no momento de descrever a situação hipotética que acarretará a incidência do tributo, caso concretizada, o legislador deve levar em conta se a situação exprime a condição econômica do agente de arcar com o seu ônus. No dizer de Leão (1999, p. 17), a observância deste princípio "tem por objetivo legitimar a tributação e graduá-la de acordo com a riqueza de cada um, de modo que os ricos paguem mais e os pobres, menos". É, em certa medida, uma especificação do princípio da igualdade ou um subprincípio que dele deriva.

Nesta linha, Stuart Mill (1983, p. 290) acrescenta que a igualdade deve ser a norma que norteia tudo aquilo que diz respeito ao governo, porque não lhe é permitido fazer nenhuma discriminação de pessoas e classes no momento de exigir um sacrifício. Com efeito, se alguém carrega uma cota de peso menor do que aquela que por justiça lhe cabe, alguma pessoa tem que carregar mais do que lhe é suportável. A igualdade da tributação expressa nessa perspectiva, igualdade de sacrifício, o que pressupõe uma exigência proporcional à riqueza de cada um. Em sua opinião, ainda que esse padrão não possa ser atingido na plenitude, deve ser o ideal almejado pelos modelos tributários.

Entretanto, apesar de o autor nomeado defender a tributação proporcional, ${ }^{6}$ manifesta-se contrário à sua incidência progressiva, ${ }^{7}$ sob o argumento de que "taxar as rendas mais altas em uma percentagem maior do que as rendas menores significa impor um tributo à iniciativa e à parcimônia, impor uma penalidade a pessoas por terem trabalhado mais duro e economizado mais do que seus vizinhos". Essa concepção, compreensível naquele momento histórico, está superada em vista de que hodiernamente os tributos têm seu fundamento na teoria da distribuição dos encargos públicos ${ }^{8}$.

Logo, vê-se que a tributação deve ser geral, devendo atingir o maior número de pessoas e o seu pagamento deve ser uniformemente feito, na medida da capacidade de cada um, de forma que cada pessoa possa contribuir com mais ou com menos para a manutenção dos serviços públicos prestados pelos poderes públicos à sociedade.

\footnotetext{
${ }^{6}$ Pelo princípio da proporcionalidade a fixação de contribuições concretas para os particulares deve ser feita em proporção às singulares manifestações de capacidade contributiva de cada qual, já que o desejado é que o tributo não seja desproporcional a ela. (VILLEGAS, 1974, p. 92) ${ }^{7}$ Pelo princípio da progressividade a alíquota se eleva à medida que aumenta a quantidade gravada. (VILLEGAS, 1974, p. 92)

${ }^{8}$ Segundo a Teoria da Distribuição dos Encargos Públicos, defendida pelos franceses Laferrière e Waline, e hoje aceita pela maioria da doutrina, "a obrigação impositiva é conseqüência da solidariedade social. Essa solidariedade é de todos os membros da comunidade, que têm o dever de sustentá-la. A obrigação individual não se mede pelas vantagens que o particular obtém do Estado, como preconizavam as teorias precedentemente analisadas. Tal obrigação se estabelece em virtude da capacidade pessoal do indivíduo de contribuir para os gastos da comunidade, como forma de fazer com que cada um participe dos mesmos, segundo suas possibilidades." (VILLEGAS, 1980, p. 11).
} 
O princípio da igualdade consiste na proibição de arbitrariedade, desproporção ou excesso, significando vedação da desigualdade consubstanciada na injustiça, na insegurança e na opressão da liberdade. Objetiva, portanto, dar unidade ao sistema jurídico, funcionando como medida, proporção ou razoabilidade, em todos os valores e princípios. Com sede explícita no texto constitucional, inclusive em seu preâmbulo, denota o anseio de elegê-lo como um valor supremo e, por conseguinte, um dos alicerces do ordenamento jurídico. A supremacia da igualdade, todavia, exige constante vigilância do legislador e do aplicador do direito para que se torne ideário factível em cada situação. Entretanto, não é incoerente pensar que, para a concretização da igualdade, pode-se fazer uso da desigualdade. Como ensinava Rui Barbosa (2003, p. 46), adotando a ideia de Aristóteles, "a regra da igualdade não consiste senão em quinhoar desigualmente aos desiguais, na medida em que se desigualam. Nesta desigualdade social, proporcionada à desigualdade natural, é que se acha a verdadeira lei da igualdade". E conclui que "tratar com desigualdade a iguais, ou a desiguais com igualdade, seria desigualdade flagrante, e não igualdade real".

Como uma especificação daquela, a igualdade tributária, da mesma forma, serve de medida, e harmoniza simultaneamente a justiça com os diversos princípios vinculados aos casos concretos. Logo, o legislador ordinário, ao deparar-se com a necessidade de instituir um tributo, deve considerar a capacidade contributiva, mas pode também sopesar outros princípios não relacionados à esfera tributária, em vista de relevante interesse social subjacente, de forma que da ponderação resulte elevação ou redução da tributação e, por consequência, seja preservado o valor que o Estado pretende proteger. Deduz-se que a igualdade tributária não está adstrita a um único fundamento, pois pode ser justificada, dentre outros, por motivos de ordem social, fiscal, financeira ou política. Vê-se que o princípio não se restringe apenas ao tratamento igualitário na aplicação das normas, mas, principalmente, na criação da lei. O princípio da igualdade dirige-se ao próprio legislador, vinculando-o à criação de um direito igual para todos os cidadãos e situações, observadas as desigualdades.

O princípio da legalidade não é uma criação moderna, mas sim um princípio que está enraizado na tradição européia, como forma de reação contra o despotismo tributário da época. Foi durante o reinado de João Sem Terra, na Inglaterra, que os barões se rebelaram contra as exigências fiscais abusivas e impuseram determinadas condições, mediante um estatuto legal que vedava a criação de tributos sem o consentimento do Conselho do Reino. Mais tarde, após a revolução de 1688, como decorrência de sua evolução, o princípio incorporou a legalidade como pressuposto essencial e indispensável, ao exigir a aprovação das normas tributárias pelo Parlamento.

Assim, o princípio da legalidade tributária, desde o seu início, surgiu com o significado de um sistema de proteção do contribuinte diante dos possíveis abusos dos governantes. Na atualidade, especialmente nos regimes 
representativos de governo, é conferido aos representantes do povo a faculdade de criar ou aumentar tributos para suprir as despesas públicas. Como a competência para a criação ou aumento de qualquer espécie tributária é exclusiva do Poder Legislativo, salvo situações excetuadas pelo texto constitucional, a norma tributária somente existe se criada mediante lei e na medida por ela criada.

Entretanto, não basta a lei formal reconhecer a existência do tributo, impondo prestações compulsórias; deverá ela consignar de forma completa e suficientemente individualizada, todos os elementos essenciais e necessários à sua exigência.

Em resumo, embora somente o legislador tenha o poder para editar a lei tributária, nela deve constar com clareza os elementos relacionados à sua criação, em especial, o fato gerador, a base de cálculo, as alíquotas e as penalidades. É que não basta à lei instituir um tributo, precisa obrigatoriamente tipificar as situações que permitem à Administração Pública exigi-lo dos contribuintes. Em outras palavras, precisa definir as hipóteses de incidência para que o fisco possa identificar e exigir dos contribuintes o seu pagamento. Portanto, o campo de abrangência de um tributo é definido pelas situações descritas na lei (hipótese de incidência) que quando ocorrem, possibilitam ao Estado, através de seu poder de império, exigir o cumprimento da obrigação de pagá-lo.

Por sua vez, o princípio da não-surpresa é decorrência dos movimentos revolucionários do século XVIII e foi expressamente proclamado pela primeira vez na Constituição da França de 1791, exigindo que as contribuições públicas fossem deliberadas e fixadas anualmente pelo Poder Legislativo. É de certa forma uma especificação do critério da certeza apresentado por Adam Smith, como imperativo para que todos conheçam com antecedência e segurança, as obrigações que lhes são impostas. O princípio da não-surpresa se materializa juridicamente, principalmente, através do princípio da anualidade, que predica a inclusão da lei tributária no orçamento anual e, pelo princípio da anterioridade da lei fiscal em relação ao exercício de sua cobrança.

Da análise destes fundamentos fica evidenciado que, embora o Estado tenha sua conduta balizada por determinados pressupostos que se observados levam a uma tributação justa, a sua ação de retirar parte do patrimônio dos particulares, decorre do poder de tributar a ele concedido pela sociedade.

Diante dessa conformação, o Estado deve dispor do aparelhamento necessário que o possibilite exigir o justo tributo, evitando as práticas lesivas aos cofres públicos que são perpetradas através de técnicas de evasão fiscal, para que possa obter recursos suficientes ao custeio das atividades que desenvolve, em especial, a de dar efetividade aos direitos fundamentais.

2 A EVASÃO FISCAL COMO PRÁTICA DE CORRUPÇÃO

Uma abordagem mais coerente para a evasão fiscal é tratá-la como espécie do gênero corrupção, pois a forma com que são praticadas e os 
efeitos que produzem as torna idênticas. Em ambos os casos ocorre a diminuição dos recursos públicos e, por consequência, prejuízos ao atendimento das demandas sociais.

Em razão disso, para uma compreensão melhor do tema, inicia-se com uma breve análise do gênero corrupção, para a seguir estabelecer uma relação com a sua espécie, a evasão fiscal.

$\mathrm{Na}$ acepção etimológica, conforme Garcia (2004, p. 440), o termo corrupção deriva do latim rumpere, equivalente a romper, dividir, gerando o vocábulo corrumpere, que por sua vez, significa deterioração, depravação ou alteração.

O fenômeno remonta à Antiguidade e não passou despercebido à própria Bíblia. ${ }^{9}$ Pode-se afirmar com segurança que, em maior ou menor grau, sempre fez parte da história da humanidade, como uma doença crônica quase incurável.

Na Grécia, a preocupação maior com a corrupção estava relacionada à degradação das virtudes que deviam ser cultivadas pelos cidadãos. Agia como agente corruptor aquele que proclamava condutas contrárias aos ideais de justiça e bem estar dos membros da cidade-estado. Como apregoava Sócrates aos seus discípulos, o homem deve se guiar pela constante busca do verdadeiro bem, agindo em conformidade com a sua consciência, visando a excelência humana. A corrupção tem então o significado de mal causado a outros homens, não apenas por meio de práticas ilícitas, com vista à obtenção de vantagem particular, mas, sobretudo por ações e palavras que contribuam para o desvirtuamento dos comportamentos sociais.

$\mathrm{Na}$ linguagem moderna, caracteriza-se principalmente como um desvio de conduta praticado por uma ou mais pessoas, visando o interesse particular, em detrimento do bem comum, envolvendo em geral, membros da administração pública. Por isso, aos olhos do leigo, a corrupção é vista como a vantagem indevida que o agente público obtém para si ou para terceiros, relegando a planos secundários os legítimos fins contemplados nas normas. Uma análise mais acurada faz ver que a corrupção não está restrita ao espaço de atuação dos poderes públicos, mas permeia toda a sociedade.

Se é nos governos ditatoriais que a corrupção encontra o ambiente mais adequado para proliferar-se, pois não existem ou são poucos os mecanismos de controle da atuação estatal, nas democracias, com a ascensão do povo ao poder e a constante alternância dos dirigentes das organizações públicas, ela tende a ser menor. Entretanto, a sua propagação

\footnotetext{
${ }^{9}$ A Bíblia Sagrada faz inúmeras referências à corrupção, a exemplo da passagem em Isaías, capítulo 1, versículos 21 a 23: "Como se transformou em prostituta a cidade fiel! Antes era cheia de direito, e nela morava a justiça; agora, está cheia de criminosos! A sua prata se tornou lixo, o seu vinho ficou aguado. Os seus chefes são bandidos, cúmplices de ladrões: todos eles gostam de suborno, correm atrás de presentes; não fazem justiça ao órfão, e a causa da viúva nem chega até eles."
} 
ocorre também nos países com debilidade democrática, em virtude das limitações dos instrumentos de controle, da inexistência de mecanismos aptos a manter a administração adstrita à legalidade, da arbitrariedade do poder e da consequente supremacia do interesse dos detentores do poder público em prejuízo do anseio coletivo.

É que como anteviu Montesquieu (1992, p. 96, 111, 114-115, 146-147), para que um Estado democrático possa consolidar os princípios que o sustentam, é preciso, sobretudo que os seus cidadãos possuam um forte sentimento de patriotismo, no sentido de amor às leis e à Pátria. Esse amor conduz a excelência dos costumes, fortalece a solidariedade e, por consequência, afasta a ambição descomedida dos interesses particulares, causa primeira da corrupção.

No Brasil, um país com uma democracia ainda frágil, vez que se trata de uma conquista recente, a corrupção é vista por diversos historiadores como desdobramento ou reflexo de fatos que remontam ao período colonial. $\mathrm{Na}$ opinião de Holanda (1995, p. 38-39), o legado português, com seus costumes e valores, influenciaram por longa data o caráter dos brasileiros. A gente brasileira herdou dos portugueses da época, uma compreensível tendência à ociosidade, por ser este um valor considerado nobilitante para um bom português. A carência moral em relação ao valor do trabalho causava, por consequência, certa tolerância e displicência às normas e uma reduzida capacidade de organização social. A solidariedade entre eles se restringia às relações de interesse no recinto doméstico, ou entre amigos.

Seguindo essa linha, Barbosa (1992, p. 2) acrescenta que essas características ainda podem ser percebidas em pequenas ações de burla da lei, com o propósito de privilegiar o interesse particular. É facilmente constatável que para muitos indivíduos, as normas legais proibitivas, não significam propriamente uma negação ou uma barreira definitiva que não possa ser transposta. Assim, por exemplo, enquanto o "não" de um guarda inglês é considerado pelo agente receptor da ordem, como definitivo, categórico e irrecorrível, o não do guarda brasileiro é interpretado, muitas vezes, como um "talvez" que, dependendo da situação, ou mesmo da conversa, pode transmudar-se para um "sim".

$\mathrm{Na}$ avaliação da autora, essa cultura de valores advém da sistemática de funcionamento da administração portuguesa, que era autoritária, paternalista, particularista e ad hoc. A legislação era confusa, detalhista e numerosa e, mesmo o Código Filipino estabelecido em 1603 mantinha idênticas peculiaridades. Como decorrência, o caráter português da época tinha como características o desrespeito às leis, diante da complexidade jurídica; a tolerância com a corrupção, resultado da baixa expectativa de serviço público honesto; e a falta de responsabilidade civil, que se resumia na ênfase acentuada nas relações pessoais de amizade e de família, importando numa valoração maior da pessoa e menos da norma. 
Independente das origens que deram causa a esses comportamentos sociais, Oliveira (1993, p. 43-44) vê a sociedade brasileira carente de princípios éticos, o que se traduz em corrupção generalizada, clientelismo, autoritarismo, demagogia de diferentes níveis, oportunismo, irresponsabilidade e prepotência como norma no exercício da administração pública. Com isso, instalou-se uma crise nos valores básicos da vida política, produzindo, por consequência, uma crise de legitimação das instituições e dos costumes vigentes.

Mas, apesar desse quadro, o autor revela-se otimista ao constatar que, sob outro prisma, vive-se um momento de choque de ideias, entre o antigo e o novo, que vem provocando, gradativamente, um senso novo de justiça, consciência maior dos direitos e da importância da união no processo de transformação da vida em comunidade.

Em determinados grupos, já se observa uma mudança de aspirações: não se trata mais simplesmente de crescer no ter e no fazer, mas de transformar a sociedade irracional. Constrói-se, a partir daqui, um novo estilo de vida, onde o problema dos fins da sociedade e do sentido da vida em comum é reposto como problema central. Os grupos alternativos estão pressionando para que se atente de novo à dignidade do homem enquanto ser essencialmente comunitário e livre. (OLIVEIRA, 1993, p. 46)

No que diz respeito às questões tributárias, a crise de valores e a corrupção possuem íntima relação com a sonegação e já caminham juntas há muito tempo. Como inferiu Omegna (1971, p. 296-297), em sua incursão pela história da economia colonial do Brasil, o sistema tributário e o aparato fiscal da época eram tão perversos que a fraude e a corrupção impregnaram-se na cultura popular como práticas comuns e aceitáveis. Diante da descrença na honestidade dos homens do governo:

[...] o suborno ao funcionário, a contravenção do fisco, o desprezo da lei, tornaram-se práticas comuns na cidade oprimida pela Fazenda insaciável d'El-Rei. A sociedade se educa no desrespeito da lei, e essa atitude se aprofunda tanto, nos séculos da colônia, que chega a transformar-se num atributo do povo, o qual desde então começou a preferir o domínio dos homens ao das leis, o chefe às idéias, o caudilho aos códigos, o carismático ao homem comum. A lei extorsiva, servida por funcionários sensíveis ao suborno, perdera a sua respeitabilidade. Por isso a sociedade colonial considerou as fraudes, o contrabando, as denegações do imposto como atos lícitos, e até mesmo dignos das simpatias gerais.

Apesar de diversos autores apontarem para uma generalização da corrupção, com raízes históricas, como herança de desterrados portugueses, não há uma fundamentação plausível que demonstre a veracidade desta assertiva. A aceitação dessa premissa legaria ao povo brasileiro um destino 
trágico e inalterável e uma justificação social para os desvios de conduta na gestão pública. A corrupção não pode ser tratada como uma fatalidade histórica que está impregnada nos valores de toda a Sociedade. Esta ideia reforça uma postura de condescendência com a ilicitude, diante da falsa percepção de que se trata de um mal crônico que a todos pode acometer. Aparenta que a corrupção se restringe a determinados grupos detentores do poder político ou financeiro.

Todavia, é visível no cotidiano do brasileiro, como traço social comum, uma exagerada tendência à tolerância com as normas estabelecidas e de desleixo com os bens públicos. Do ponto de vista dos tributos, esse comportamento produz resultados graves, porque dificulta a tomada de consciência do cidadão, sobre a sua importância como agente participativo e colaborador no combate à sonegação e aos desvios de dinheiro público. Nenhuma administração alcança resultados expressivos na redução da evasão fiscal e da corrupção sem a participação fiscalizadora da Sociedade.

Ao se tratar das práticas de corrupção é importante inferir que o dinheiro público pode ser desviado dos cofres estatais antes do seu ingresso, por meio da sonegação, ou após a sua entrada, através da apropriação ilícita ou da má aplicação. Desta maneira, os valores devidos ao Estado a título de tributos não declarados ou não pagos não perdem a sua natureza pública. Sob esta ótica, a sonegação deve ser entendida como uma espécie grave de corrupção, e aqueles que colaboram ou facilitam para a sua realização, não exercitando, por exemplo, o direito de exigir documentos fiscais, na condição de consumidores, são em certo sentido co-responsáveis pelos resultados. Essa lógica aparenta ser equivocada devido à forma complacente com que a sonegação é apresentada à opinião pública. É preciso destacar que os montantes que envolvem a evasão de tributos ${ }^{10}$ são, por certo, extremamente superiores aos desvios realizados através de outras formas de corrupção, ${ }^{11}$ frequentemente divulgados pela mídia com grande ênfase.

Apesar dos vultosos valores envolvidos nas práticas tributárias lesivas ao patrimônio público, é flagrante a falta de mecanismos legais eficazes para a sua cobrança nos executivos fiscais. As alternativas adotadas com frequência pelos governos, restringem-se à concessão de anistias aos devedores, premiando os maus contribuintes e desestimulando o cumprimento das leis tributárias. A despeito da utilidade que estes benefícios possam

\footnotetext{
${ }^{10}$ Se adotados os parâmetros de Pellizzari de que a sonegação varia entre 30\% e 40\% do valor dos tributos arrecadados no país, a evasão produz desvios de recursos públicos em montante superior a R\$ 200 bilhões de reais por ano. (PELLIZZARI, 1990, p. 45)

11 Embora as diversas práticas de corrupção devam representar valores bastante inferiores àqueles desviados por meio da sonegação de tributos, os prejuízos à população também são enormes. De acordo com estudos do Ministério da Justiça, se considerado apenas o que a União investe anualmente em compra de insumos e em obras públicas, as fraudes nestas licitações causam um prejuízo ao erário público estimado entre R\$ 25 bilhões e R\$ 40 bilhões. (BARROS, 2007, p. 29-30)
} 
propiciar em determinadas circunstâncias especiais, em geral, acabam por institucionalizar uma concorrência predatória entre os contribuintes cumpridores das obrigações tributárias e aqueles que após descumpri-las recebem ainda os favores do Estado. Isto reforça no imaginário social a percepção de certa impunidade aos contribuintes infratores.

Contudo, as soluções não podem se restringir à mera implementação de rigorosas sanções aos fraudadores ou o fortalecimento dos sistemas legais de cobrança dos devedores. Como explica Giannetti (2007, p. 94-96), adotando o pensamento de Aronson, a motivação para o cumprimento das normas estabelecidas pelo Estado, a exemplo das tributárias, pode ser motivada por três fatores: o temor da sanção, a identificação social ou a internalização de valores.

O temor da sanção faz com que parte dos contribuintes cumpra com as obrigações fiscais em razão do rigor da pena que lhes será imposta em caso de descumprimento comprovado pelo fisco.

Num nível distinto encontram-se uma parcela dos contribuintes que observam as normas legais motivados pela "identificação social". Neste caso, não praticam determinadas ações consideradas erradas ou ilícitas pela sociedade para não receberem uma reprovação social. Observa-se que, por exemplo, enquanto os atos de desrespeito ao meio ambiente atingiram, em grande parte, esse nível de reprovação, as práticas explícitas de sonegação, como não entregar documento fiscal aos consumidores, são plenamente toleráveis e aceitas.

Por fim, tem-se o nível mais elevado de conscientização em que a razão para cumprir as normas decorre de uma "internalização de valores". O indivíduo que atingiu esse grau de percepção não acata as normas legais pelo temor da punição ou da reprovação social, mas com base numa reflexão ética interior.

Compreender como se concretiza a adesão social às normas é fundamental para criação de instrumentos que permitam uma mudança da perspectiva meramente punitiva para uma visão preventiva e, sobretudo, educativa.

É preciso também avaliar as consequências no cumprimento das normas pelo cidadão, quando os poderes públicos não estão plenamente ordenados e estruturados em bases sólidas, de forma a promover a justiça social. A questão é saber se o Estado, por meio de sua organização e dos seus administradores, pode influenciar no aumento da corrupção, incluída a sonegação, quando não está inteiramente a seu serviço. Montesquieu (1992, p. 146-147), ao analisar as diversas formas de governo, constata que quando os princípios que os fundamentam estão corrompidos, as melhores leis tornam-se más e pouco respeitadas pelo povo; do contrário, quando os princípios estão preservados, mesmo leis ruins ou de pouca efetividade, produzem bons efeitos, graças à confiança popular na atuação estatal. 
Para Rawls (2002, p. 504), não há dúvida, uma sociedade política bem ordenada e regulada por uma concepção pública de justiça, implica que os seus membros também tenham um desejo forte, e normalmente efetivo, de agir em conformidade com estes mesmos princípios. Em resumo, assevera que "quando as instituições são justas, os indivíduos que participam dessas organizações adquirem o senso correspondente de justiça, e o desejo de fazer a sua parte para mantê-las".

Embora a sociedade seja considerada a criadora do Estado, não é incomum que uma minoria o utilize para fins ilícitos. Quando a corrupção instala-se no governo, o Estado não cumpre integralmente a sua função, o que faz com que, em parte, reproduza-se na sociedade a fragilidade dos valores de justiça. No Brasil, aparenta que os elevados níveis de corrupção são causados por um modelo de Estado mal estruturado, excessivamente burocrático, clientelista, permeado de falhas de gestão e brechas legais que favorecem a prática de "favores" e "jeitinhos".

Por isso, em certo sentido, a resistência dos contribuintes de direito aos tributos e o desleixo dos cidadãos consumidores em participar ativamente, mediante a prática de ações que evitem a sonegação, está relacionada à forma como é gerida a coisa pública. Como exclamava Sáinz de Bujanda (1962, p. XIX), quantas vezes "a fraude não é senão uma torpe e amarga reação frente a um Estado em que se perdeu a fé". Deste modo, o desrespeito às leis tributárias pode ser reduzido a níveis mais aceitáveis, quando os gestores públicos conduzem a administração com respeito às normas e aos valores éticos inerentes ao bem público.

Com aporte nestas considerações, infere-se que a corrupção, incluída a sonegação, possui direta relação com a estruturação do Estado e a forma com que seus dirigentes o administram. Um Estado que não se concretiza em bases justas e voltado ao bem comum, governado muitas vezes para o interesse de poucos, cria um distanciamento da comunidade que, não se percebendo a ele integrada, apresenta um comportamento apático em relação à coisa pública. Porém, quando a sociedade brasileira estabelece uma resistência aos tributos, seja na condição de contribuinte de direito ou como contribuinte de fato, em vista da corrupção e malversação do dinheiro público, combate um mal com outro mal, do que resulta um círculo vicioso que degenera ainda mais os valores que a sustentam.

3 A CONTRIBUIÇÃO DOS TRIBUTOS PARA A EFETIVIDADE DOS DIREITOS FUNDAMENTAIS

Para se avaliar a importância dos tributos na efetivação dos direitos fundamentais, faz-se necessário estabelecer, inicialmente, uma reflexão que permita uma avaliação aproximada do contexto em que se inserem, apesar da vagueza e aparente tendência redutora da sua concretização no Brasil.

Parte-se da concepção preliminar de que os direitos fundamentais são aqueles que se encontram positivados ou garantidos no ordenamento 
jurídico de um Estado, notadamente nos textos constitucionais, porque permitem, deste modo, exigir dos poderes públicos uma atuação que oportunize a sua concretização em níveis considerados adequados.

Adota-se essa simplificação, sem adentrar na análise doutrinária ${ }^{12}$ que envolve a evolução, conceito e contornos dos direitos fundamentais, porque o objetivo central da pesquisa é precisamente estabelecer uma relação entre o seu déficit de efetividade diante da corrosão de receitas produzida pela evasão fiscal.

Na Constituição de 1988, os direitos sociais se encontram em capítulo distinto dos demais, o que tem sido suficiente para questionar a sua inclusão como pertencentes à categoria de direitos fundamentais. Para Garcia (2008, p. 132), esse equívoco tem como causa a fundamentação dos direitos fundamentais segundo a ideologia da teoria liberal, talvez por receio ou preconceito à sua perspectiva socialista. Em sua opinião, é necessária a superação dos conflitos ideológicos entre as concepções liberais e socialistas, estabelecendo uma nova configuração dos direitos fundamentais, identificando-os como transideológicos ${ }^{13}$.

Reconhecer esta nova concepção implica em ampliar o âmbito de exigibilidade da atuação estatal, enfrentando objetivamente os problemas sociais que afligem o país, em decorrência do déficit de efetivação dos direitos sociais.

Nessa linha, para Barroso (2000, p. 106), "é puramente ideológica, e não científica, a resistência que ainda hoje se opõe à efetivação, por via coercitiva, dos chamados direitos sociais". Isto se evidencia com clareza quando se avalia a estruturação do Título que contempla os Direitos e Garantias Fundamentais, distinguindo-os apenas em capítulos distintos, para efeitos didáticos, os direitos e deveres individuais e coletivos dos direitos sociais.

Este é o pensamento de Sarlet (2005, p. 86-87), ao asseverar que:

A acolhida dos direitos fundamentais sociais em capítulo próprio no catálogo dos direitos fundamentais ressalta, por sua vez, de forma incontestável sua condição de autênticos direitos fundamentais, já que nas cartas anteriores os direitos sociais se encontravam positivados no capítulo da ordem econômica e social, sendo-lhes, ao menos

\footnotetext{
12 Para uma compreensão adequada da evolução e amplitude dos direitos fundamentais vide: PÉREZ LUÑO, Antonio Enrique. La Tercera Generación de Derechos Humanos. Navara: Editorial Aranzadi, 2006, p. 25-48; PECES-BARBA, Gregorio. Curso de Derechos Fundamentales: teoria general. Madrid: Universidad Carlos III, 1995, p. 146-198.

${ }^{13}$ O termo transideológico é composto pelo designativo "trans", com o sentido de movimento para além de algo, e a expressão "ideologia", aqui utilizada na sua acepção restritiva, que Bobbio define como o "conjunto de ideias e de valores respeitantes à ordem pública e tendo como função orientar os comportamentos políticos coletivos. (BOBBIO; MATTEUCCI; PASQUINO, 2004, p. 585)
} 
em princípio e ressalvadas algumas exceções, reconhecido caráter meramente programático, enquadrando-se na categoria de normas de eficácia limitada.

Estabelecidos os aspectos básicos para a compreensão da amplitude e abrangência dos direitos fundamentais, é possível correlacioná-los com os tributos, visando demonstrar, especialmente, os efeitos nefastos que a prática da sonegação produz sobre àqueles.

Os tributos não devem ser analisados apenas como simples decorrência do poder de império do Estado, ou mero sacrifício para os cidadãos, mas como o contributo indispensável a uma vida em comum e próspera para todos os membros da sociedade. Com efeito, para cumprir as suas funções e proporcionar a fruição de grande parte dos direitos fundamentais, o Estado tem de socorrer-se das receitas tributárias. A opção que se amolda a esse modelo é o Estado Fiscal, ${ }^{14}$ mas estruturado de forma que uns paguem mais e outros menos. Assim, todos os cidadãos são portadores de direitos, mas somente as pessoas com capacidade contributiva têm o dever fundamental de pagar tributos. Como assevera Nabais (2004, 185-186), esse é, seguramente, um dos preços mais baratos a pagar pela manutenção da liberdade e de uma sociedade civilizada.

O dever fundamental de pagar tributos caracteriza-se como uma categoria constitucional que expressa valores e interesses comunitários, pois traz subjacente a realização de interesses de todo o grupo social, como saúde e educação, dentre outros. Portanto, é um dever que está fundado na ideia de solidariedade ${ }^{15}$. Noutro lado, os direitos visam resguardar ou garantir benefícios ou prerrogativas do cidadão. Assim, ambos se relacionam porque a efetivação dos direitos depende do financiamento dos poderes públicos.

A constatação que se extrai dessa nova conformação social é que a cidadania não se esgota com a fruição de direitos civis, políticos e sociais, mas se amplia para exigir também do cidadão, o cumprimento dos deveres fundamentais. Sob o ponto de vista do financiamento dos serviços públicos, o dever de pagar tributos apresenta-se como um dos sustentáculos centrais dos poderes estatais. Evidencia-se então um forte elo de ligação entre os deveres e os direitos fundamentais. Nesta linha, os tributos passam a ser

\footnotetext{
${ }^{14}$ A expressão Estado fiscal é utilizada para caracterizar os países contemporâneos, cujas necessidades financeiras são essencialmente cobertas por recursos oriundos dos impostos arrecadados. (NABAIS, 2004, p. 191-192)

${ }^{15}$ Etimologicamente, o termo solidariedade tem as suas raízes na expressão latina solidarium, que vem de solidum e soldum, com o sentido de inteiro ou compacto. Daí que a solidariedade se refere ao sentimento de pertencer a um grupo de indivíduos para a realização de fins que só na sociedade pode-se atingir. Disto resulta que ela pode ser entendida como uma relação de co-responsabilidade e partilha que vincula cada um dos indivíduos aos demais membros da comunidade. É assim, um liame que se estabelece entre os indivíduos, objetivando a mútua ajuda nas dificuldades e nas necessidades. (GRECO; GODOI, 2005, p. 111-112)
} 
concebidos não mais sob um enfoque individual de quem contribui, mas por meio de uma relação indissociável do coletivo. Pagar tributos ou zelar pelo cumprimento desta obrigação é um dever que está vinculado à noção de cidadania plena ${ }^{16}$.

Deste modo, se os homens conceberam e estruturaram o Estado com o propósito de estabelecer uma coabitação relativamente harmoniosa e de apoio mútuo, certamente decidiram que a forma de financiá-lo, deveria dar-se por meio de tributos. Como afirma Villegas, o surgimento dos tributos deve ser buscado "na mesma necessidade que desde épocas pretéritas, levou os integrantes duma comunidade a criarem o Estado, como única forma de obterem uma convivência ordeira e coesa". Por esse prisma, diante da conformação quase universal dos Estados fiscais, que são custeados essencialmente pelas receitas tributárias, a evasão fiscal se apresenta quase como um paradoxo, porque se caracteriza, em certo sentido, como uma rejeição do cidadão ao próprio Estado, que é o promotor e garantidor de grande parte dos direitos fundamentais.

Lamentavelmente, esta é a realidade brasileira. É que no Brasil, a obrigação de pagar tributos não parece estar impregnada nos valores do cidadão como um dever fundamental. É facilmente constatável um ambiente de tolerância para com os contribuintes que deixam de cumprir as exigências fiscais. Do lado de quem é instado a pagar, há mesmo uma cultura de que se trata de uma imposição que pode ser relegada a um plano secundário. Não é incomum ouvir-se de empresários, sem nenhum constrangimento, que deixaram de recolher os tributos porque havia outros compromissos mais importantes, como pagamento de fornecedores, empréstimos bancários ou de empregados. Isto demonstra que a obrigação de contribuir com tributos não está incorporada definitivamente à vida nacional como um dever imprescindível ao financiamento das políticas públicas.

Mas esta visão de que a efetividade dos direitos fundamentais está, em certo grau, intimamente ligada à arrecadação dos tributos, não tem o propósito de fundamentá-los em aspectos meramente econômicos. Esta é uma redução grave e que precisa ser afastada para se evitar o extremo de se invalidar um direito, unicamente com base em valoração de natureza orçamentária.

A escassez de recursos como fator inerente à atuação do Estado, é um limitador natural da atuação estatal. Diante dessa barreira, vem crescendo a ideia de aplicabilidade da teoria da reserva do possível, ${ }^{17}$ como um inibidor

\footnotetext{
${ }^{16}$ Cidadania plena é concebida neste artigo não apenas no sentido de que o cidadão deve ter assegurados os direitos civis, políticos e sociais, mas, também, como portador de deveres, a exemplo do dever de pagar tributos.

17 De acordo com essa teoria, "a efetividade dos direitos sociais a prestações materiais estaria sob a reserva das capacidades financeiras do Estado, uma vez que seriam direitos fundamentais dependentes de prestações financiadas pelos cofres públicos". (SARLET; TIMM, 2010, p. 29).
} 
do desempenho do Estado de concretizar efetivamente direitos fundamentais em decorrência das limitações orçamentárias.

Respeitadas as correntes doutrinárias ${ }^{18}$ que destacam a necessidade de uma compreensão da capacidade financeira dos entes públicos no atendimento das demandas públicas e de que os direitos demandam custos, discorda-se desta linha de pensamento. Há, no dizer de Canotilho (2008, p. 266), um núcleo essencial de prestações garantidoras de direitos sociais que não podem ser afastadas por "reservas de lei", decorrentes de omissões legislativas ou "reserva do possível", em termos econômicos ou financeiros. São prestações irredutíveis porque afrontam a dignidade da pessoa humana.

Para isto, parte-se do pressuposto de que o orçamento público é um documento de prioridades, de forma que nele devem constar em ordem decrescente as necessidades de uma determinada coletividade. Os direitos fundamentais contemplam as aspirações mais elevadas do ser humano e, em decorrência disso, precisam destacar-se como demandas inafastáveis, ainda que para isso seja necessário postergar ou inviabilizar obras ou serviços em áreas menos prioritárias.

Ainda assim, se durante o exercício da execução orçamentária, novas prioridades surgirem em decorrência, por exemplo, de sentenças judiciais exigindo o fornecimento pelo Estado de medicamentos a determinadas pessoas, o benefício não poderá ser afastado pela falta de dotação orçamentária, pois o orçamento público não é uma peça imutável. Diante de situações desta natureza, comprovada a ausência ou deficiência de recursos, a Constituição de 1988 autoriza a criação de créditos suplementares ou especiais, ${ }^{19}$ observadas as fontes ${ }^{20}$ expressamente definidas na Lei $4.320 / 64$, que estabelece as normas para elaboração e execução do orçamento.

No Brasil, se avaliada a distribuição de recursos para as diversas finalidades, evidencia-se distorções que precisam ser corrigidas para uma maior priorização das necessidades fundamentais dos cidadãos. A título de

\footnotetext{
${ }^{18}$ Cita-se como adepto desta corrente Flávio Galdino. Vide a obra: GALDINO, Flávio. Introdução à Teoria dos Custos dos Direitos: direitos não nascem em árvores. Rio de Janeiro: Lumen Juris, 2005.

${ }^{19} \mathrm{O}$ artigo 41, da Lei 4.320/64, define como créditos suplementares, os destinados a reforço de dotação orçamentária, e créditos especiais, os destinados a despesas para as quais não haja dotação orçamentária específica. De forma didática, pode-se dizer que quando os recursos destinados a determinada finalidade social especificada no orçamento forem insuficientes, o Estado pode utilizar-se de créditos suplementares e, de outro modo, nos casos de ausência de rubrica no orçamento, o Estado poderá recorrer a créditos especiais.

${ }^{20} \mathrm{O}$ artigo 43 , $\S 1^{\circ}$, da Lei 4.320/64, estabelece que as fontes de recursos para a obtenção de créditos suplementares e especiais são: o superávit financeiro apurado em balanço patrimonial do exercício anterior; os recursos provenientes de excesso de arrecadação; os recursos resultantes de anulação parcial ou total de dotações orçamentárias ou de créditos adicionais, autorizados em Lei, e; o produto de operações de credito autorizadas, em forma que juridicamente possibilite ao poder executivo realizá-las.
} 
exemplo, basta comparar os gastos executados no ano de 2010, pelo governo federal, para pagamento de juros e amortização da dívida pública ${ }^{21}$ que totalizaram, aproximadamente, $\mathrm{R} \$ 373$ bilhões, enquanto para a saúde foram alocados somente R $\$ 56$ bilhões. ${ }^{22}$

Do ponto de vista dos destinatários das prestações sociais, aparenta que determinados direitos fundamentais não deveriam se caracterizar como uma obrigação do Estado para todos os cidadãos indistintamente. Cite-se o exemplo do fornecimento de medicamentos aos portadores de determinada enfermidade. Neste caso, embora a Constituição de 1988 prescreva expressamente que a saúde é direito de todos ${ }^{23}$, o acesso universal e igualitário que proclama, não deveria ser no sentido de que, independentemente da capacidade de cada um, ricos e pobres pudessem usufruir gratuitamente das políticas sociais voltadas aos serviços desta natureza. A igualdade de acesso amplo trata-se, a nosso ver, de uma igualdade relativa que admite diferenciações, não arbitrárias, mas fundadas em critérios que permitam a adoção de tratamento desigual na medida dessas desigualdades.

Sob este viés, ao Estado se imporia o dever de atender esta demanda àqueles que não possuem capacidade financeira para arcar com o seu custo, contudo, não estaria obrigado a atender a mesma demanda àqueles que são detentores de condições econômicas suficientes para a sua fruição. Esta seria uma conduta que estaria plenamente voltada ao atendimento do bem comum, ainda que pela abstenção parcial, nos casos em que o cidadão tem plenas condições de socorrer-se sem apoio estatal.

O que se pretende demonstrar é que o bem comum é obra de todos, tanto da sociedade por meio dos seus cidadãos, como do Estado, através das ações dos seus governos. Quer se dizer que, apesar da cultura popular impingir ao Estado a responsabilidade por grande parte das políticas direcionadas ao atingimento de condições dignas de vida, todos têm 0 dever de cooperar para esse desígnio. Os cidadãos devem contribuir, seja cumprindo as obrigações estatuídas pelas regras jurídicas, a exemplo da obrigação de recolher os tributos sob sua responsabilidade, seja espontaneamente por meio de condutas, ações ou serviços que contribuam para o bem estar individual ou do grupo familiar.

\footnotetext{
${ }^{21}$ A dívida pública é a soma de tudo aquilo que todos os órgãos do Estado brasileiro devem, incluindo o governo federal, estados, municípios e empresas estatais. A dívida pública se subdivide em dívida interna e dívida externa, dependendo se as instituições financeiras credoras forem nacionais ou internacionais.

${ }^{22}$ Relatório resumido da execução orçamentária do governo federal e outros demonstrativos. Tesouro Nacional, Brasília, dez. 2010. Disponível em: <http://www.stn.fazenda.gov.br>. Acesso em 25 abr. 2011.

${ }^{23}$ De acordo com o artigo 196, da Constituição de 1988, "a saúde é direito de todos e dever do Estado, garantido mediante políticas sociais e econômicas que visem à redução do risco de doença e de outros agravos e ao acesso universal igualitário às ações e serviços para sua promoção, proteção e recuperação.
} 


\section{CONSIDERAÇÕES FINAIS}

A pesquisa objetivou estabelecer uma reflexão acerca da amálgama que une os direitos fundamentais com o dever de pagar tributos. No Brasil, embora se esteja vivenciando um momento histórico, em que os cidadãos estão despertando para os direitos constitucionais que lhes são assegurados, não há a mesma conscientização sobre a importância dos tributos, como fonte de financiamento de direitos como saúde, educação, segurança, dentre outros.

Essa aparente indiferença e mesmo conivência com a sonegação fiscal, pode ser percebida nas ações simples dos cidadãos consumidores que não se afetam com as práticas visíveis de evasão fiscal e sequer procuram contribuir para evitá-la, exigindo, por exemplo, comprovantes fiscais de aquisição de produtos ou serviços.

Avaliando o desvio de recursos que é perpetrado por meio da sonegação de tributos, evidencia-se uma similaridade com a corrupção, distinguindo-se somente quanto ao momento, pois naquela, ocorre antes do ingresso dos recursos nos cofres públicos e, nesta, depois de já pertencerem ao Estado.

A questão se apresenta mais complexa porque a evasão fiscal produz também um desequilíbrio da concorrência do mercado, fazendo com que outros contribuintes venham a aderir à mesma técnica para poder competir em condições de igualdade, gerando um círculo vicioso que degenera ainda mais a frágil estrutura tributária.

Por outro lado, é perceptível uma insatisfação da sociedade com a forma como o Estado gerencia os recursos dos tributos, seja pelas sistemáticas práticas de corrupção, má gestão ou reduzida eficiência. Disto se infere que a corrupção, incluída a sonegação, possui direta relação com a forma com o Estado é gerenciado. Um Estado que não se concretiza em bases justas e voltado ao bem comum, governado muitas vezes para o interesse de poucos, cria um distanciamento do cidadão que, não se percebendo a ele integrado, apresenta um comportamento apático em relação à coisa pública.

Diante desse paradigma, colocando-se de um lado o dever fundamental, daqueles que são eleitos pela lei como contribuintes, de pagar tributos e, de outro, a sociedade como portadora de direitos financiados pelo Estado, denota-se que o descumprimento das obrigações tributárias influencia diretamente no nível de efetividade dos direitos fundamentais.

Um fato incontroverso que se extrai deste estudo é que, no cotidiano, as classes mais atingidas pelas práticas lesivas aos cofres públicos são as que dependem mais intensamente das políticas públicas, especialmente em áreas como a da saúde, saneamento básico e assistência social. Nestes casos, apesar de imperceptível ao cidadão comum, a falta de recursos causada por desvios, pode significar a diferença entre viver ou morrer para muitas pessoas. Essa constatação demonstra que a corrupção e a sonegação produzem efeitos tão deletérios que afrontam a dignidade da pessoa humana. 


\section{REFERÊNCIAS}

BARROSO, Luís Roberto. O Direito Constitucional e a Efetividade de suas Normas. Limites e Possibilidades da Constituição Brasileira. Rio de Janeiro: Renovar, 2000.

BARBOSA, Lívia. O Jeitinho Brasileiro. Rio de Janeiro: Campus, 1992.

BARBOSA, Ruy. Oração aos Moços. São Paulo: JG Editor, 2003.

BARROS, João de. Lobby: a ante-sala da corrupção. Caros Amigos, São Paulo, $n^{\circ}$ 123, jun. 2007, p. 29-30.

BÍBLIA. Português. Bíblia Sagrada. Tradução de Ivo Storniolo et al. São Paulo: Paulus, 1990.

BOBBIO, Norberto; MATTEUCCI, Nicola; PASQUINO, Gianfranco. Dicionário de Política. Tradução de Carlos Nelson Coutinho et. al. 12. ed., v. 1, Brasília: Editora Universidade de Brasília, 2004.

BRASIL. Constituição (1988). Constituição da República Federativa do Brasil. Brasília, DF: Senado, 1988.

BRASIL. Lei Federal n 4.320, de 17 de março de 1964.

BUJANDA, Fernando Sainz de. Hacienda $Y$ Derecho: Introducción al Derecho Financeiro de Nuestro Tiempo. v. I, Madri: Instituto de Estúdios Políticos, 1962.

CANOTILHO, José Joaquim Gomes. Estudos sobre Direitos Fundamentais. 1. ed., 3. tir. São Paulo: Editora Revista dos Tribunais; Portugal: Coimbra Editora, 2008.

COÊLHO, Sacha Calmon Navarro. Curso de Direito Tributário Brasileiro. Rio de Janeiro: Forense, 1999.

COSTA, Regina Helena. O Princípio da Capacidade Contributiva. 2. ed., São Paulo: Malheiros Editores, 1996.

DALLARI, Dalmo de Abreu. O Futuro do Estado. São Paulo: Saraiva, 2001.

GALDINO, Flávio. Introdução à Teoria dos Custos dos Direitos: direitos não nascem em árvores. Rio de Janeiro: Lumen Juris, 2005.

GARCIA, Emerson. A Corrupção: uma visão jurídico-sociológica. Revista dos Tribunais, v. 820, São Paulo, fev. 2004.

GARCIA, Leite Marcos. O Debate Inicial sobre os Direitos Fundamentais: aspectos destacados da visão integral do conceito. Revista do Instituto de Pesquisas e Estudos, Bauru, v. 46, nº 50, jul./dez., 2008.

GIANNETTI, Eduardo. Vícios Privados, Benefícios Públicos?: A Ética na Riqueza das Nações. São Paulo: Companhia das Letras, 2007.

GRECO, Marco Aurélio; GODOI, Marciano Seabra de (orgs.). Solidariedade Social e Tributação. São Paulo: Dialética, 2005.

HOLANDA, Sérgio Buarque de. Raízes do Brasil. 26. ed., São Paulo: Companhia das Letras, 1995.

LEÃO, Armando Zurita. Direito Constitucional Tributário: O Princípio da Capacidade Contributiva. São Paulo: Editora Juarez de Oliveira, 1999.

MARCELINO, Júlio César. Reflexões da Pós-Modernidade: Estado, Direito e Constituição. Florianópolis: Conceito Editorial, 2008.

MILL, John Stuart. Princípios de Economia Política: com algumas de suas aplicações à filosofia social. Tradução de Luiz João Barúna, São Paulo: Abril Cultural, 1983. 
MONTESQUIEU, Charles de Secondat. O Espírito das Leis: as formas de governo, a federação, a divisão dos poderes, presidencialismo versus parlamentarismo. 2. ed., aum. São Paulo: Saraiva, 1992.

MORAES, Bernardo Ribeiro de. Compêndio de Direito Tributário. v. 2, 3. ed., rev., aum. e atual. Rio de Janeiro: Forense, 2002.

NABAIS, José Casalta. O Dever Fundamental de Pagar Impostos: contributo para a compreensão constitucional do estado fiscal contemporâneo. Coimbra: Almedina, 2004.

OLIVEIRA, Manfredo Araújo de. Ética e Racionalidade Moderna. São Paulo: Loyola, 1993.

OMEGNA, Nelson. A Cidade Colonial. 2. ed., Brasília: EBRASA, 1971.

PECES-BARBA, Gregorio. Curso de Derechos Fundamentales: teoria general. Madrid: Universidad Carlos III, 1995.

PELLIZZARI, Deoni. A Grande Farsa da Tributação e da Sonegação. Petrópolis: Vozes, 1990.

PÉREZ LUÑO, Antonio Enrique. La Tercera Generación de Derechos Humanos. Navara: Editorial Aranzadi, 2006.

RAWLS, John. Uma Teoria da Justiça. Tradução de Almiro Pisetta e Lenita Maria Rímoli Esteves. São Paulo: Martins Fontes, 2002.

SARLET, Ingo Wolfgang. A Eficácia dos Direitos Fundamentais. Porto Alegre: Livraria do Advogado, 2005.

SARLET, Ingo Wolfgang (Org.); TIMM, Luciano Benetti (Org.) et al. Direitos Fundamentais: orçamento e "reserva do possível". 2. ed., ver. e ampl. Porto Alegre: Livraria do Advogado, 2010.

SMITH, Adam. A Riqueza das Nações: investigação sobre sua natureza e suas causas. Tradução de Winston Fritsch. v. II, São Paulo: Nova Cultural, 1996.

Tesouro Nacional. Disponível em: <http://www.stn.fazenda.gov.br>. Acesso em 25 abr. 2011.

TORRES, Ricardo Lobo. Curso de Direito Financeiro e Tributário. 7. ed., Rio de Janeiro: Renovar, 2000.

Tratado de Direito Constitucional Financeiro e Tributário: Os Direitos Humanos e a Tributação: Imunidades e Isonomia. v. III, Rio de Janeiro: Renovar, 1999.

VILLEGAS, Héctor B. Direito Penal Tributário. Tradução de Elisabeth Nazar et al. São Paulo: Ed. Resenha Tributária, 1974. 